\title{
Cobertura florestal e qualidade da água na bacia hidrográfica do rio Jucu, estado do Espírito Santo, Brasil
}

The jungle cover and water quality in the Jucu river basin, state of Espírito Santo, Brazil

\author{
B. S. Gardiman Junior ${ }^{1 *} ;$ L. T. Simoura ${ }^{2}$ \\ ${ }^{1}$ Professor da Coordenadoria de Meio Ambiente do Instituto Federal do Espírito Santo, CEP: 29.395-00, Campus \\ Ibatiba, Estado do Espírito Santo, Brasil \\ ${ }^{2}$ Engenheira Ambiental e de Segurança do Trabalho, CEP: 29-101-300, Vila Velha, Espírito Santo, Brasil
}

benvindo.gardiman@ifes.edu.br

(Recebido em 30 de abril de 2015; aceito em 07 de dezembro de 2015)

\begin{abstract}
Os fragmentos florestais remanescentes da mata atlântica influenciam indubitavelmente na qualidade da água dos rios que drenam. Objetivando analisar o percentual de cobertura florestal e os impactos antrópicos sobre os parâmetros de qualidade da água e compará-las em relação à resolução CONAMA ${ }^{\circ}$ 357/2005, estudaram-se duas sub-bacias: rio Formate e rio Jucu Braço Sul, no qual pertencem a Bacia Hidrográfica do rio Jucu. Para subsidiar a discussão utilizou-se o IQA da CETESB e o Software ArcGIS 9.3 para elaborar a base de dados espaciais. Os resultados expõem que o Rio Jucu (Braço Sul) com 68\% de cobertura florestal apresentou água com índice de qualidade "boa" em todos os pontos e o Formate com $41 \%$ de cobertura florestal entre "regular" e "ruim". Destaca-se também que as variáveis que se apresentaram acima do limite estabelecido pela resolução CONAMA 357/2005 foram $\mathrm{DBO}_{5}, \mathrm{P}_{\text {total }}, \mathrm{N}_{\text {total }}$ e Colifirmes Termotolerantes principalmente na sub-bacia do rio Jucu, que representam poluição antrópica. Por fim, o estudo aponta a influência do ambiente externo sobre a qualidade da água, relevando a importância da cobertura florestal como meio de proteção aos mananciais, e assim priorizar sua segurança hídrica.

Palavra-chave: bacia hidrográfica do rio Jucu, Cobertura florestal, qualidade da água.
\end{abstract}

The remaining wood fragments of Atlantic Jungle, undoubtedly influence the water quality of the rivers draining of. Aiming to analyze the percentage of forest cover and human impacts on water quality parameters and than compare them with the respect Resolution CONAMA 357/2005, have been studied two sub-basins: Formate river and river Jucu South Arm, in which Jucu river Watershed belongs. To support the discussion used the IQA CETESB and ArcGIS 9.3 software to design the spatial database. The results state that the Jucu River (South Arm) with $68 \%$ forest cover showed a water quality index "good" in all points and the format with $41 \%$ forest cover between "regular" and "bad." Also noteworthy is that the variables presented above the limit established by CONAMA Resolution 357/2005 were BOD5, Ptotal, total $\mathrm{N}$ and thermotolerant coliforms mainly in the sub-basin of the river Jucu, representing anthropogenic pollution. Finally, The study seeks to address the influence of the external environment on the quality of water, emphasizing the importance of wood cover as a means of watershed protection, and thus prioritize their water security.

Keyword: Jucu river watershed, forest cover, water quality.

\section{INTRODUÇÃO}

A manutenção da cobertura florestal é primordial à preservação da qualidade das águas de um manancial [1]. Os inúmeros processos que ocorrem dentro de uma bacia de drenagem de um corpo hídrico podem refletir sobre algumas variáveis de qualidade da água, sendo que estas referem-se a uma série de parâmetros físicos e químicos que apresentam significado ambiental da influência direta da integridade da bacia hidrográfica [2]. Além disso, podem ser modificadas por diversos fatores atuantes, estando relacionadas diretamente com o uso e ocupação do solo, permitindo, muitas vezes, diagnosticar possíveis causas dos impactos ambientais sobre os recursos naturais $[3,4]$. 
Cita-se que a retirada da vegetação e posterior conversão do uso da terra pelo homem constituem os maiores agentes modificadores da cobertura da terra e desencadeia uma série de alterações significativas no meio físico e no ciclo da água [5].

A Bacia Hidrográfica do rio Jucu recebe uma alta carga de nutrientes, tanto orgânicos como industriais, e agrotóxicos originados principalmente pelo escoamento superficial das áreas cultivadas de café e banana. Às margens do rio encontram-se instaladas diversas atividades impactantes sem planejamento adequado, tais como: extração de areia para construção civil, emissão de resíduos sólidos domésticos, industriais e hospitalares; lançamentos de efluentes de pocilgas, currais e abatedouros de aves, sem o devido tratamento [6].

Segundo Lara [7], para minimizar os efeitos danosos ao ambiente todos os estados deveriam promover um programa de conservação de mananciais com objetivo de recuperar e conservar os mananciais de abastecimento público, adequando o uso e manejo dos recursos naturais, minimizando os efeitos poluidores, além de definir e implantar áreas especialmente protegidas em mananciais de abastecimento.

As áreas florestadas não perturbadas são a melhor condição desejada do ponto de vista da proteção dos recursos hídricos. O monitoramento hidrológico de microbacias com floresta natural serve como referência para comparação com outras microbacias impactadas, simultaneamente monitoradas. Diversos estudos são realizados nestas condições, avaliando as diferentes intervenções nas microbacias e as alterações sobre as variáveis de qualidade da água, $[8,9,10,11]$.

Além disso, alguns autores afirmam que bacias com maiores percentuais de cobertura florestal produzem água de melhor qualidade e consequentemente um custo menor de tratamento $[3,5,7]$.

Neste sentido, este estudo teve como objetivo relacionar a cobertura florestal e os impactos antrópicos sobre os parâmetros da qualidade da água provenientes de duas microbacias hidrográficas e seus diferentes percentuais de cobertura florestal, buscando subsidiar discussões sobre a importância da cobertura florestal em mananciais de abastecimento público, como recurso ambiental a ser refletido pela sociedade e entidades legais.

\section{MATERIAL E MÉTODOS}

A área em estudo compreende oito pontos de monitoramento da qualidade da água, sendo três pontos na microbacia do rio Jucu Braço Sul, (JUC2C005, JUC2C008 e JUC1C009) e cinco pontos na microbacia do rio Formate (FOR1C001, FOR1E008, FOR1C010, FOR1C012 e FOR1C015), localizados entre $20^{\circ} 00^{\prime} 00^{\prime \prime}$ e $20^{\circ} 27^{\prime} 22^{\prime \prime}$ de latitude e entre $41^{\circ} 14^{\prime} 42^{\prime \prime}$ e $40^{\circ} 23^{\prime}$ $42^{\prime \prime}$ de longitude, com altitude variando entre 10 a 1800 metros acima do nível do mar, conforme pode ser apreciado na Figura 1 e na Tabela 1: 


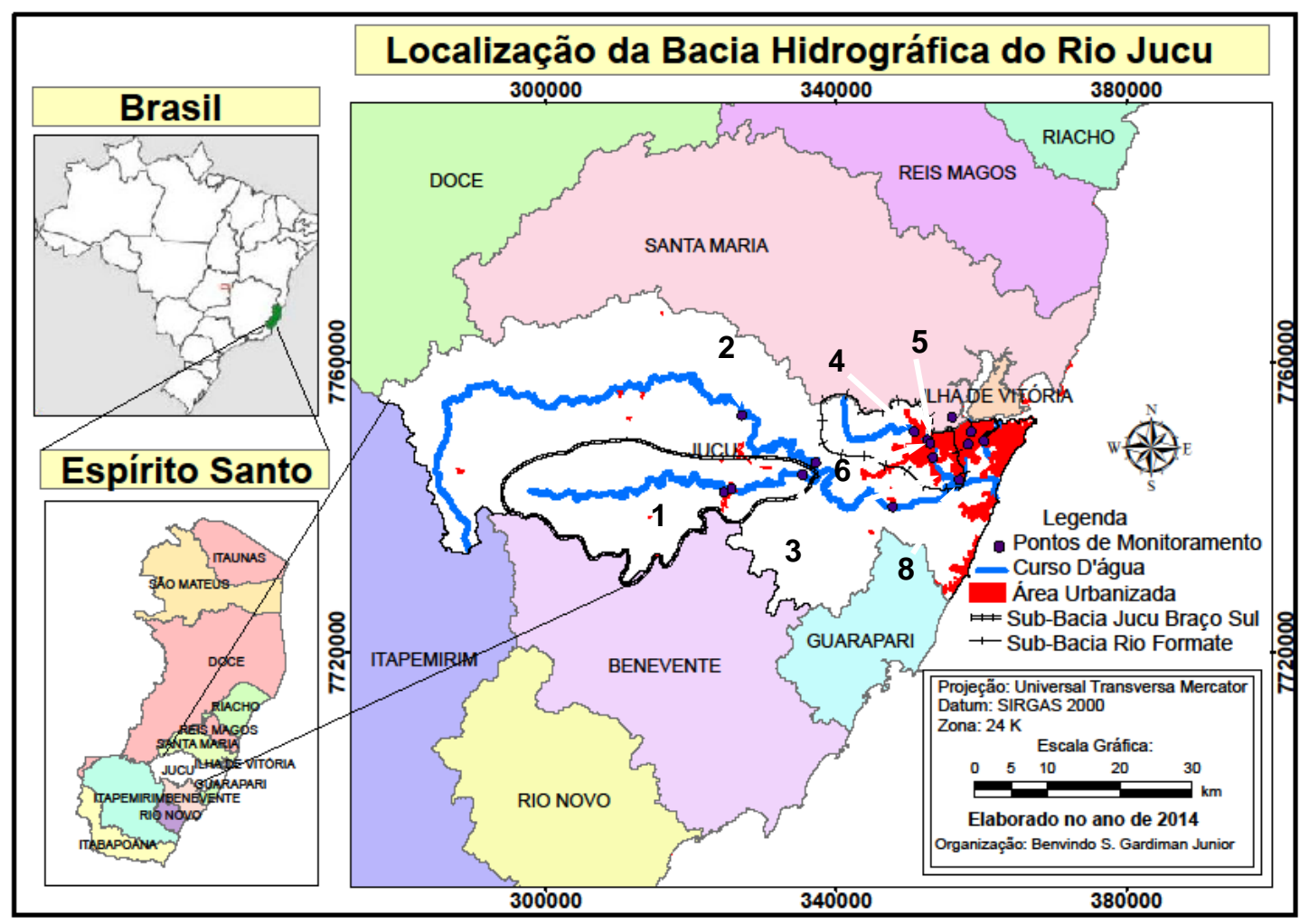

Figura 1. Destaque para a Bacia Hidrográfica do Rio Jucu no Estado do Espírito Santo, as duas subbacias e os pontos de monitoramento. Fonte: Os Autores.

Tabela 1: Localização dos pontos monitorados

\begin{tabular}{|c|c|c|c|c|}
\hline $\begin{array}{l}\text { Código do } \\
\text { Ponto }\end{array}$ & $\begin{array}{c}\text { Código } \\
\text { no mapa }\end{array}$ & $\begin{array}{l}\text { Coordenada } \\
\mathbf{x}\end{array}$ & $\begin{array}{c}\text { Coordenada } \\
\mathbf{y}\end{array}$ & Localização \\
\hline JUC2C005 & 1 & 324520 & 7742071 & $\begin{array}{l}\text { No Braço Sul, a saída de Marechal } \\
\text { Floriano, sob a ponte na BR-262. }\end{array}$ \\
\hline JUC2C008 & 2 & 325603 & 7742551 & $\begin{array}{l}\text { No Braço Sul, sob a ponte de } \\
\text { madeira em Marechal Floriano. }\end{array}$ \\
\hline JUC1C009 & 3 & 335392 & 7744465 & $\begin{array}{l}\text { No Braço Sul, no caminho que liga } \\
\text { a usina hidrelétrica do Jucu a BR- } \\
\text { 262, Domingos Martins. }\end{array}$ \\
\hline FOR1C001 & 4 & 350764 & 7750425 & $\begin{array}{c}\text { Na Ponte de pedestres entre } \\
\text { Marcílio de Noronha e Piranema. }\end{array}$ \\
\hline FOR1E008 & 5 & 352621 & 7749312 & $\begin{array}{c}\text { Sob a ponte na divisa de Cariacica e } \\
\text { Viana (BR-262). }\end{array}$ \\
\hline FOR1C010 & 6 & 352991 & 7748796 & $\begin{array}{c}\text { Na divisa dos bairros São Francisco } \\
\text { e Vila Betânia em Cariacica. }\end{array}$ \\
\hline FOR1C012 & 7 & 353361 & 7746834 & $\begin{array}{c}\text { À } 2 \mathrm{~km} \text { a jusante do ponto } \\
\text { FOR } 1 \mathrm{C} 010 .\end{array}$ \\
\hline FOR1C015 & 8 & 356956 & 7743762 & $\begin{array}{c}\text { No ponto final do ônibus Caçaroca } \\
\text { em Cariacica. }\end{array}$ \\
\hline
\end{tabular}

O clima da região segundo a classificação de Köppen é Aw, ou seja, tropical úmido, com estação chuvosa no verão e seca no inverno [12]. A precipitação média gira em torno de 1.200 $\mathrm{mm}$ anuais, concentrando-se na primavera e no verão, entre outubro a março, quando ocorre de 65 a $80 \%$ do total de chuvas.

As amostras de água foram coletadas em quatro campanhas (Março, Junho, Agosto, Novembro) registrando se houve ou não evento de chuva nas últimas 24 horas. Obedeceu-se, para cada variável a se analisar, os procedimentos descritos na norma técnica NBR 9898 [13] de 
coleta e preservação das amostras. Os equipamentos utilizados, bem como os métodos de detecção empregados, seguiram os preceitos da American Public Health Association [14].

Os parâmetros de qualidade de água monitorados foram: Demanda Bioquímica de Oxigênio - $\mathrm{DBO}_{5}$, Fósforo total - P total, Nitrogênio total- N total, Sólidos Totais, Temperatura, Turbidez e Coliformes Termotolerantes, a fim de relacioná-los à resolução CONAMA 357/2005 [16] e em sequência à porcentagem de cobertura florestal.

Com o intuito de subsidiar as discussões sobre a poluição das águas, utilizou-se o Índice de Qualidade de Água (IQA) desenvolvido pela National Sanitation Foundation - NSF dos Estados Unidos e usado em outros países como o Brasil e a Inglaterra [3]. Normalmente é calculado pelo produtório ponderado das qualidades de água correspondentes aos parâmetros selecionados [15] (Equação 1).

$$
I Q A=\prod_{i=1}^{n} q_{i}{ }^{w i}
$$

em que: IQA é o Índice de qualidade de água, um número entre 0 e 100; qi é a qualidade do $i$-ésimo parâmetro, um número entre 0 e 100 e wi é o peso correspondente ao $i$-ésimo parâmetro, um número entre 0 e 1, atribuído em função da sua importância para a explicação da variabilidade global da qualidade das águas da região.

Para avaliação do IQA foram utilizados os resultados das análises das amostras de água superficiais coletadas seguindo o protocolo de classificação utilizado pela CETESB (2008) que estabelece as classes: Ótima (79 < IQA $\leq 100)$; Boa $(51<\mathrm{IQA} \leq 79)$; Regular $(36<\mathrm{IQA} \leq 51)$; Ruim $(19<\mathrm{IQA} \leq 36)$, Péssima (IQA $\leq 19)$. O uso de indicadores físico-químicos da qualidade da água consiste no emprego de variáveis que se correlacionam com as alterações ocorridas na microbacia, sejam essas de origem antrópica ou natural [17].

Como o estado do Espírito Santo na época do estudo ainda não havia aprovado os respectivos enquadramentos que se refere à classificação dos cursos d'água, estes foram enquadrados em classe 2 conforme Art. 42 do CONAMA 357/2005 [16]. Na Tabela 2 contempla a unidade e o valor limite das variáveis analisadas neste estudo, conforme classificação já citada.

Tabela 2: Valores Limites do CONAMA 357 - Classe 2 água doce

\begin{tabular}{ccc}
\hline Parâmetros & Unidade & Valor \\
\hline $\begin{array}{c}\text { Demanda Bioquímica de } \\
\text { Oxigênio }-\left(\mathbf{D B O}_{5}\right)\end{array}$ & $\mathrm{mg} \mathrm{L}^{-1}$ & $<5 \mathrm{mg} \mathrm{L}^{-1} \mathrm{O}_{2}$ a $20{ }^{\circ} \mathrm{C}$ \\
Fósforo Total $-\mathbf{P}$ total & & $<0,050 \mathrm{mg} \mathrm{L}^{-1}$ (ambiente \\
& $\mathrm{mg} \mathrm{L}^{-1}$ & intermediário) \\
Nitrogênio Total $-\mathbf{N}$ total & $\mathrm{mg} \mathrm{L}^{-1}$ & $<3,7 \mathrm{mg} \mathrm{L}^{-1} \mathrm{~N}$ \\
Turbidez & UNT & $<100 \mathrm{UNT}^{-10}$ \\
Coliformes Termotolerantes & Número médio provável / & $<1.000 \mathrm{NMP} / 100 \mathrm{ml}$ \\
& $100 \mathrm{ml}$ & \\
\hline
\end{tabular}

A fim de relacionar o percentual de cobertura florestal de cada Sub-bacia à qualidade das águas, utilizam-se neste estudo o software ARCGIS 9.3 [18] para a elaboração da base de dados espaciais e aerofotos da área de estudo referentes a 2008 cedidas pelo Instituto Estadual de Meio Ambiente (IEMA), com escala 1:35.000 e resolução espacial de $1 \mathrm{~m}$ [19]. Além disso, utilizaram-se também cartas do IBGE 1978 com escalas 1/50.000 e 1/100.000 e pontos georreferenciados obtidos durante as campanhas de campo com auxílio de GPS no Sistema de Projeção UTM, Datum WGS84, zona 24S para auxiliar na delimitação das bacias hidrográficas.

A classificação do uso e ocupação do solo foi determinada por meio da identificação dos alvos de vegetação presentes empregando-se, para tanto, a classificação supervisionada da imagem via máxima verossimilhança (MAXVER), o que permite que o classificador para associar um pixel particular, a uma determinada classe ou regiões de semelhança entre os níveis de cor, conforme também realizado por Wrublack et al. [20]. Este método é mais eficiente porque as classes de treinamento são utilizadas para estimar a forma da distribuição dos pixels 
contidos em uma classe no espaço de $n$ bandas. Após a classificação, realizou-se a vetorização dos dados para calcular a porcentagem da área ocupada por floresta.

Para a análise dos dados estatisticamente empregou-se o coeficiente de variação entre os 4 valores IQA's registrados ao longo do ano, dado pela Equação 2.

$\mathrm{CV}=\frac{\mathrm{x}}{\mathrm{s}}$

onde:

s é o desvio padrão; x é a média dos dados e CV é o coeficiente de variação.

Como o coeficiente de variação analisa a dispersão em termos relativos, ele será dado em \%. Quanto menor for o valor do coeficiente de variação, mais homogêneos serão os dados, ou seja, menor será a dispersão em torno da média. De uma forma geral, se o CV for menor ou igual a $15 \%$ será baixa dispersão (dados homogêneos); entre 15 e 30\% média será a dispersão e se for maior que $30 \%$ será alta dispersão (dados heterogêneos).

\section{RESULTADOS E DISCUSSÃO}

A Tabela 3 apresenta o percentual de cobertura florestal e os Índices de Qualidade da Água IQA nas sub-bacias estudadas. Observa-se que a sub-bacia do rio Jucu Braço Sul possui 68,88\% de cobertura florestal e apresentou IQA com classificação de "boa" em todos os pontos, enquanto que a do rio Formate apresentou 41,18\% de cobertura florestal e indicou IQA "boa" apenas no primeiro ponto e nos demais classificados de regular a "ruim".

Tabela 3: Índice de Qualidade de Água e cobertura florestal do rio Jucu Braço Sul e rio Formate

\begin{tabular}{ccccccc}
\hline Corpo Hídrico & $\begin{array}{c}\text { Ponto de } \\
\text { coleta }\end{array}$ & $\begin{array}{c}\text { Média } \\
\text { anual - } \\
\text { IQA }\end{array}$ & IQA & $\begin{array}{c}\text { Coeficiente } \\
\text { de } \\
\text { Variação }\end{array}$ & $\begin{array}{c}\text { Cobertura } \\
\text { florestal }\end{array}$ & $\begin{array}{c}\text { Área } \\
\text { (ha) }\end{array}$ \\
\hline \multirow{3}{*}{ Rio Jucu - Braço Sul } & JUC2C005 & 64 & Boa & 7,55 & & \\
& JUC2C008 & 58 & Boa & 5,45 & 68,88 & $39.177,0$ \\
& JUC1C009 & 61 & Boa & 18,96 & & \\
& FOR1C001 & 57 & Boa & 13,33 & & \\
& FOR1E008 & 35 & Ruim & 23,21 & & \\
Rio Formate & FOR1C010 & 41 & Regular & 22,85 & 41,18 & $10.103,0$ \\
& FOR1C012 & 31 & Ruim & 23,56 & & \\
& FOR1C015 & 43 & Regular & 20,33 & & \\
\hline
\end{tabular}

A qualidade das águas dos pontos classificados como boa, geralmente são encontradas em rios que mantêm condições naturais, ou seja, que possivelmente não recebem efluentes domésticos e industriais e nem sofrem severos processos de degradação. Tais características não peculiares à área do rio Formate, que nesse contexto, sofrem diversas influências antrópicas, tanto em menor grau, como no caso de atividades agropecuárias, quanto em níveis mais elevados, como às relacionadas ao processo de urbanização $[6,21]$.

Ainda nesse contexto, a qualidade da água no rio Formate, ao decorrer dos pontos à jusante, foi sendo classificada como de regular a ruim. Nestes pontos observa-se que a qualidade da água piorou de forma considerável e o percentual de cobertura florestal é menor em comparação com a sub-bacia do rio Jucu Braço Sul. Além disso, outro fator se deve certamente a proximidade às áreas de urbanização como pode ser observado na Figura $1 \mathrm{em}$ vermelho, onde muitas residências e pequenas indústrias ainda lançam seus efluentes in natura nos cursos d'água [6].

Na Figura 2 apresenta as médias das 4 campanhas para cada ponto referente ao parâmetro $\mathrm{DBO}_{5}$ nas duas microbacias. 


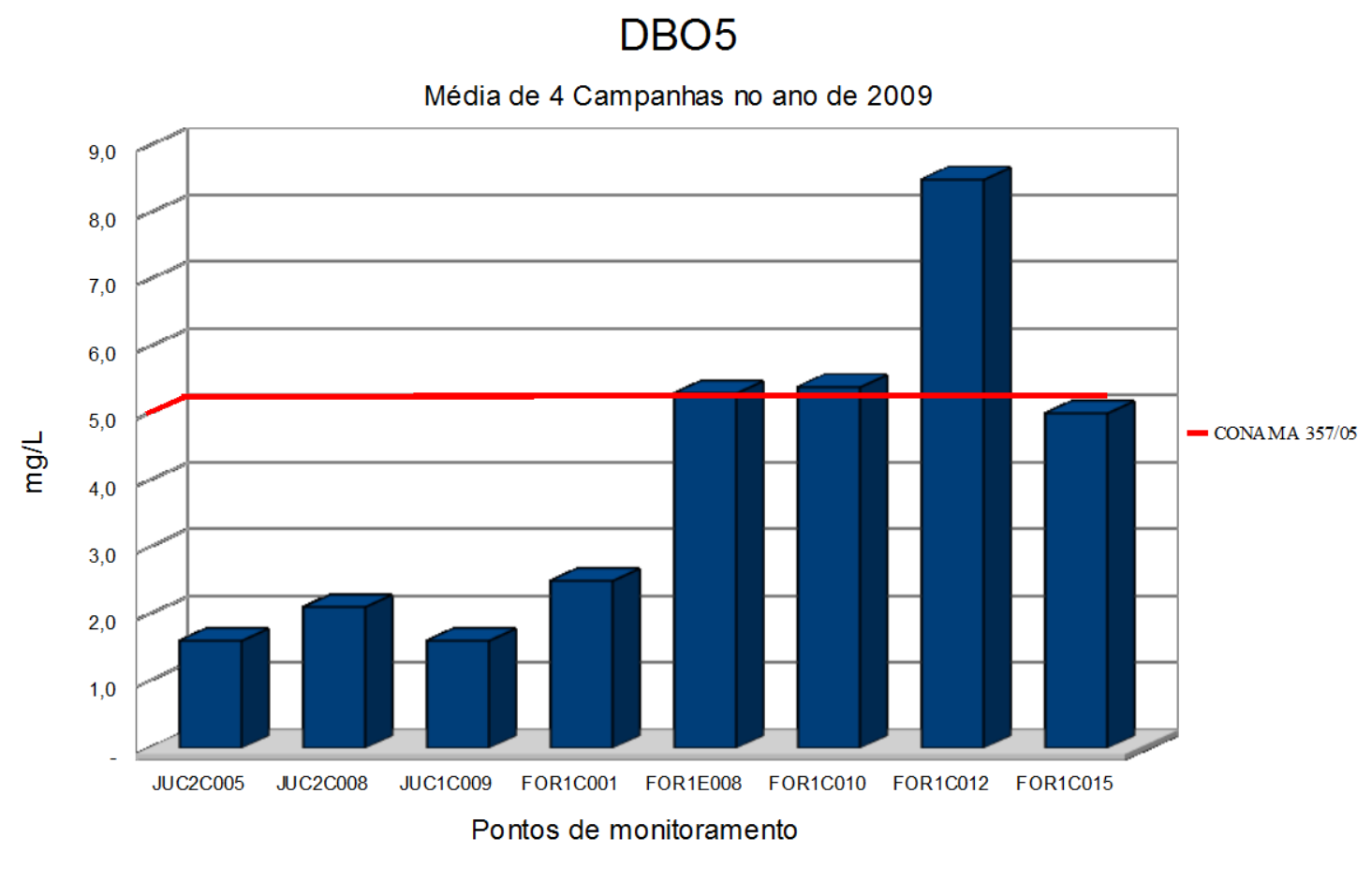

Figura 2: DBO5 em cada ponto de monitoramento nas sub-bacias.

Conforme se observa na Figura 2, os pontos que apontam níveis aceitáveis de $\mathrm{DBO}_{5}$ e melhor atende a classificação de referência são: o JUC2C005, JUC2C008 e JUC1C009 que pertencem a sub-bacia do rio Jucu Braço Sul, considerando o padrão de referência do CONAMA 357/2005 [16] para a classificação de águas doce classe 2, ilustrado na linha vermelha, o nível de $\mathrm{DBO}_{5}$ é de até $5 \mathrm{mg} \mathrm{L}^{-1}$ de $\mathrm{O}_{2}$. Esses pontos encontram-se em áreas rurais e com cobertura florestal próximas à margem como pode ser apreciado na Figura 3, mas o mesmo não pode ser dito para os níveis de $\mathrm{DBO}_{5}$ nos pontos de monitoramento: FOR1E008, FOR1C010, FOR1C012 que pertencem ao rio Formate. Em estudo de Zonta et al. [22] nas águas do rio Alegre, no sul do estado do Espírito Santo, estes autores observaram deterioração na qualidade das águas nos meses de chuva, devido ao aumento da turbidez e da DBO nas águas estudadas, na qual a qualidade variou de ruim a média, estando relacionadas diretamente com o uso e ocupação do solo, permitindo, muitas vezes, diagnosticar possíveis causas dos impactos ambientais sobre os recursos naturais [3, 4]. Nunes et al. [23] também encontraram elevadas concentrações de DBO num monitoramento realizado na Bacia do rio Turvo em Viçosa. Para eles, os efluentes urbanos lançados sem qualquer tipo de tratamento, provocam queda da qualidade da água, sendo refletivo na DBO. 


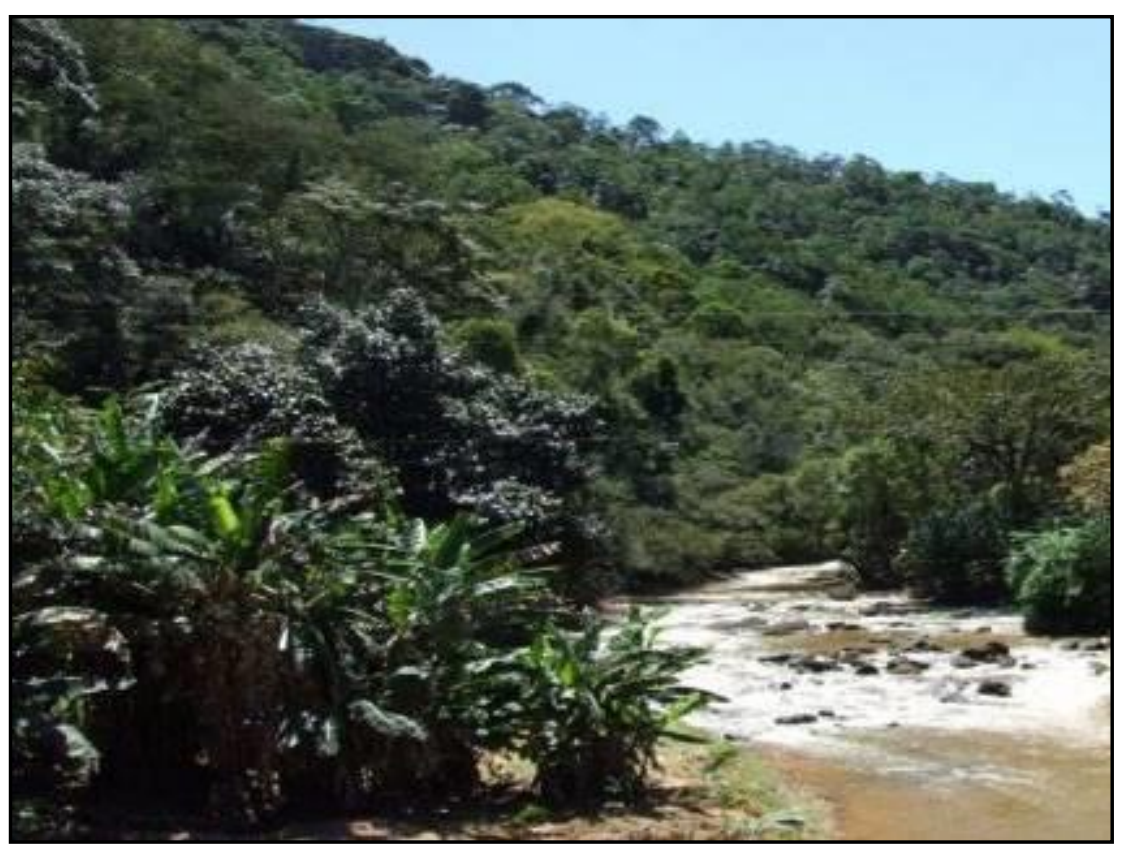

Figura 3: Foto do Rio Jucu Braço Sul. Fonte: Carlos Alberto, 2009.

O ponto FOR1C012 destoa dos demais e chega até $8,5 \mathrm{mg} \mathrm{L}^{-1}$ de $\mathrm{DBO}_{5}$, ademais pontos da sub-bacia do rio Formate que encontram-se mais próximos da linha do padrão de referência do CONAMA 357/2005 para rios classe 2. Por se localizar numa área urbana e possuir menos cobertura florestal, o ponto FOR2C012 aponta indícios de lançamento de esgotos in natura. Para Campello et al. [24], os lançamentos de esgoto doméstico e resíduos provenientes da pecuária contribuem para altos valores de DBO.

Considerando o padrão de referência do fósforo total, a Figura 4, as apresenta que em todos os pontos monitorados os valores de fósforo total acima da linha de referência do CONAMA $357 / 2005$, conforme ilustrado na linha vermelha.

\section{P Total}

Média de 4 Campanhas no ano de 2009

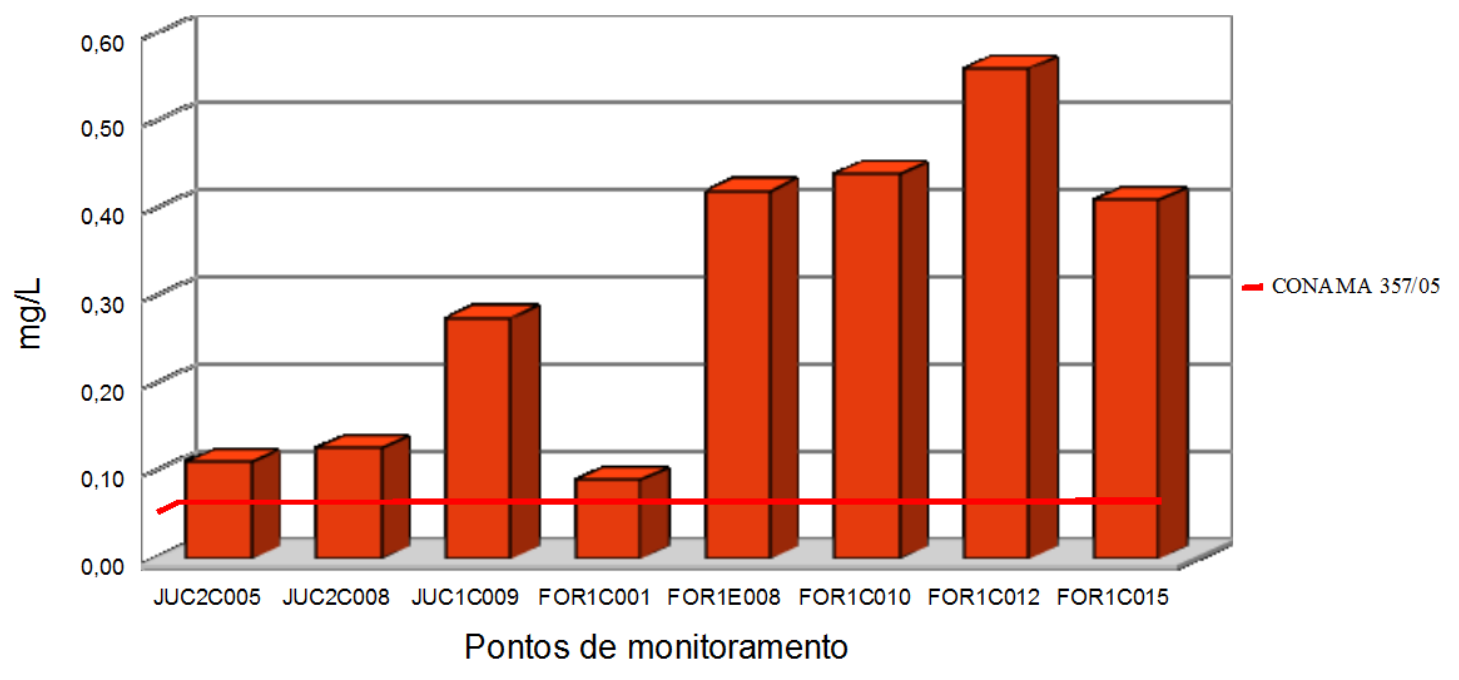

Figura 4: Pontos de monitoramento do Fósforo Total.

A sub-bacia do rio Jucu Braço Sul apresenta valores menores de fósforo total em relação à sub-bacia do rio Formate. Seu ponto de maior valor foi de $0,25 \mathrm{mg} \mathrm{L}^{-1}$ no ponto JUC1C009, 
último ponto desta. Para Terra et al. [25] em um estudo desenvolvido nesta mesma microbacia, a localização deste ponto no rio Jucu Braço Sul, segue ao lado do centro de Marechal Floriano, que por sua vez despeja esgoto in natura, sem qualquer tratamento prévio. Ainda de acordo com esse autor, em ambientes com fluxo intermediário de água, como é o caso do rio Jucu Braço Sul, o valor máximo de fósforo permitido é de $0,05 \mathrm{mg} \mathrm{L}^{-1}$. Campello et al. [24] concorda que valores elevados de fósforo são responsáveis por induzir processo de eutrofização.

Já na sub-bacia do rio Formate alguns pontos (FOR1E008, FOR1C010, FOR1C012 e FOR1C015) encontra-se com altos valores, possivelmente pela localização dos pontos, por se tratar de uma área urbana que pode afetar a qualidade da água dos referidos pontos de monitoramento. Para Tucci [26], níveis não controlados de fósforo ocasionam a eutrofização do rio, o que pode indicar também que é uma área que se encontra contaminada com essa substância e desprotegida desta exposição.

Na Figura 5 é possível analisar as médias de nitrogênio total. Conforme ilustrado na linha vermelha, a partir do CONAMA 357/2005 para classificação de águas doce classe 2, o padrão para esse parâmetro é de até $3,7 \mathrm{mg} \mathrm{L}^{-1}$, considerando $\mathrm{pH}$ menor ou igual a 7,5.

Os níveis de nitrogênio total expressam resultados diferentes para cada sub-bacia, por exemplo, o nível de nitrogênio total na microbacia do rio Formate mostrou valores cerca de 4 vezes maiores do que nos pontos de monitoramento do rio Jucu Braço Sul.

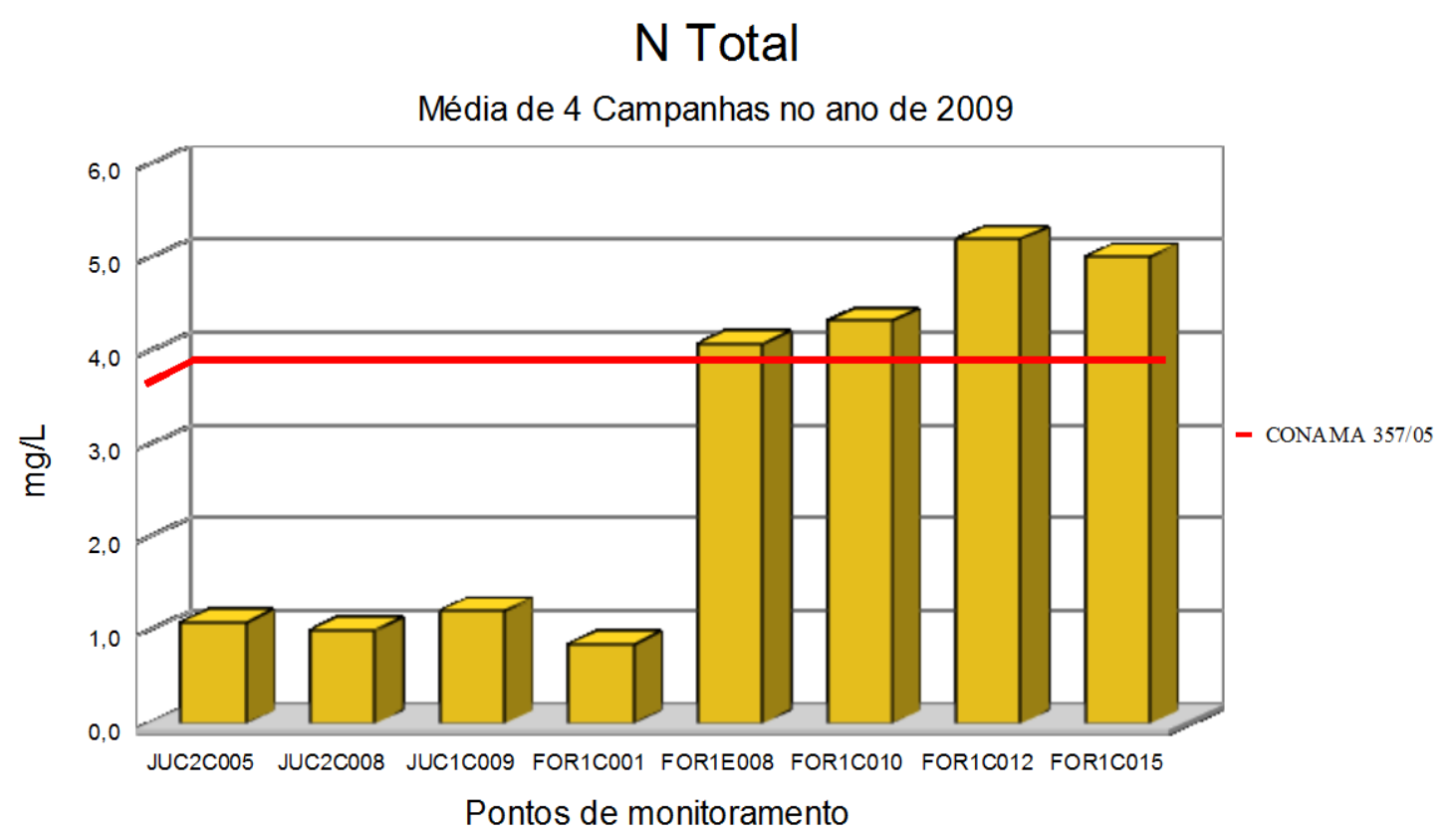

Figura 5: Pontos de monitoramento do Nitrogênio Total.

Verifica-se a exposição de grandes cargas de nitrogênio nos pontos do rio Formate, de até 5 $\mathrm{mg} \mathrm{L}^{-1}$ no ponto FOR1C012, que em alta concentração contribui para a eutrofização do sistema aquático e provoca o excessivo crescimento de plantas aquáticas. Contudo, os níveis de nitrogênio nos pontos do rio Jucu Braço Sul, apresentara-se com teores menores nos pontos JUC2C008, chegando aproximadamente $1 \mathrm{mg} \mathrm{L}^{-1}$, nos pontos JUC2C005 e JUC1C009, assim como também o ponto FOR1C001 do rio Formate, que é um ponto de cabeceira e mais distante da urbanização. Para Lima [27], a mata ciliar atua no sentido de filtrar do escoamento superficial cerca de 33\% de nitrogênio total, pelo processo de absorção pela vegetação ciliar, sendo o restante devido às transformações bioquímicas do nitrogênio que ocorrem nas condições saturadas da zona ripária, como registra a sub-bacia do rio Jucu Braço Sul, que possui maior valor percentual de cobertura florestal.

Quanto aos pontos de monitoramento referente ao rio Formate, as altas concentrações de nitrogênio foram observadas em todos os seus pontos (FOR1C001, FOR1E008, FOR1C010, 
FOR1C012 e FOR1C015), assim como às do fósforo, evidenciam lançamentos sistemáticos de esgoto sanitário, bem como, correlação positiva entre a urbanização dessa microbacia e os elevados teores dessas substâncias. Para Von Sperling [3], o nitrogênio pode ter origem antropogênicas: como despejos domésticos, industriais, excrementos de animais e fertilizantes. Srinivasan et al. [28] acreditam, que com vegetação nativa bastante degradada, em épocas das altas taxas de pluviosidade, poder-se registrar o aumento nas concentrações de nitrato, seja uma consequência do carreamento de materiais das camadas superficiais do solo ou do próprio despejo.

A Figura 6 exibe as médias das 4 campanhas no ano de 2009 para cada ponto.

\section{Temperatura}

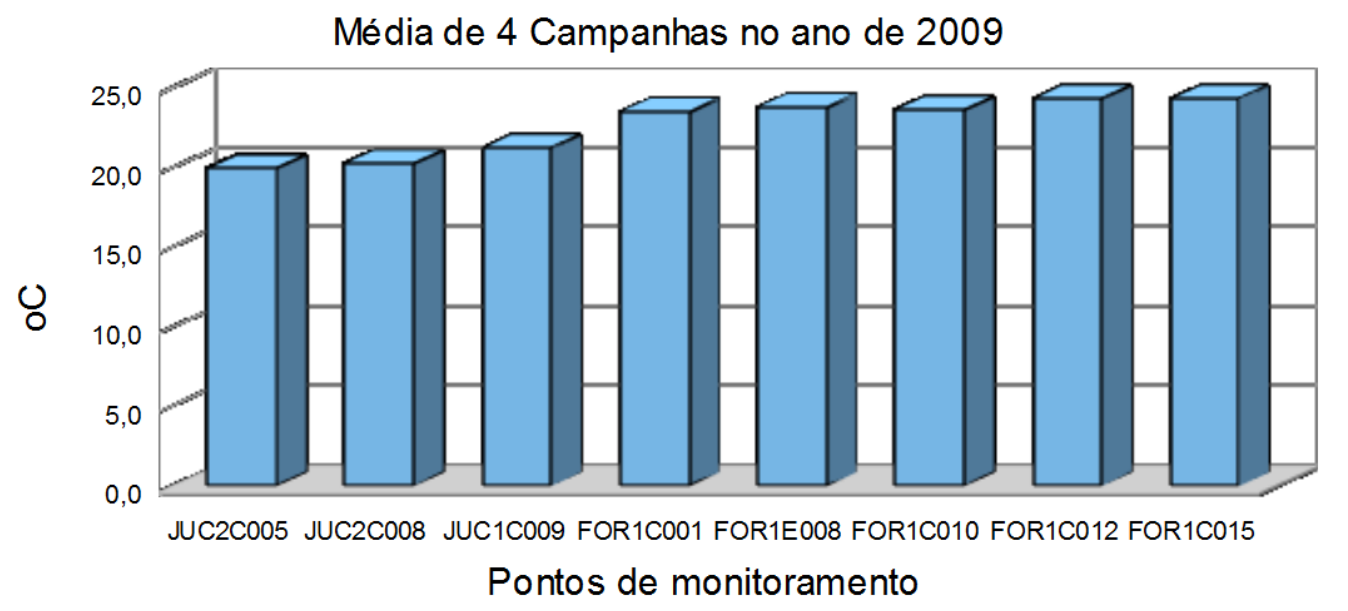

Figura 6: Pontos de monitoramento da Temperatura em graus Celsius.

Observa-se que os pontos a montante do rio Jucu Braço Sul apresentam menores temperaturas, em torno de $19^{\circ} \mathrm{C}$, com diferença significativa ao valor apresentado na sub-bacia do rio Formate, de $24,3{ }^{\circ} \mathrm{C}$. Para Lima [27], os ecossistemas formados pelas matas ciliares desempenham suas funções hidrológicas, que através de suas copas, interceptam e absorvem a radiação solar, contribuindo para a estabilidade térmica dos pequenos cursos d'água, como expõe os resultados da sub-bacia do rio Jucu Braço Sul.

Por outro lado, a sub-bacia do rio Formate há um aumento da temperatura gradativamente, possivelmente à proximidade dos centros urbanos. Para Tucci [26], a grande quantidade de superfícies impermeáveis que absorvem parte da energia solar aumenta a temperatura ambiente, produzindo ilhas de calor na parte central dos centros urbanos, onde predomina o concreto e o asfalto. $\mathrm{O}$ asfalto, devido a sua cor, absorve mais energia devido à radiação solar do que as superfícies naturais e do concreto, a medida que a sua superfície envelhece tende a escurecer e aumentar a absorção de radiação solar. Estudos realizados por alguns autores afirmam que a manutenção da vegetação ciliar é a maneira mais efetiva de prevenir aumentos da temperatura da água $[17,22,30]$.

Quanto aos sólidos totais, a Figura 7 expressa as médias das 4 campanhas de cada ponto. Observa-se que não houve uma variação significativa entre os valores de sólidos totais nos pontos, exceto no ponto JUC2C005, que na sua terceira campanha realizada no dia 13 de agosto de 2009 , teve uma concentração de $1580 \mathrm{mg} \mathrm{L}^{-1}$, muito supostamente à chuva ocorrida nos últimos dias como registrado durante a coleta e o apresentado na Figura 8. 


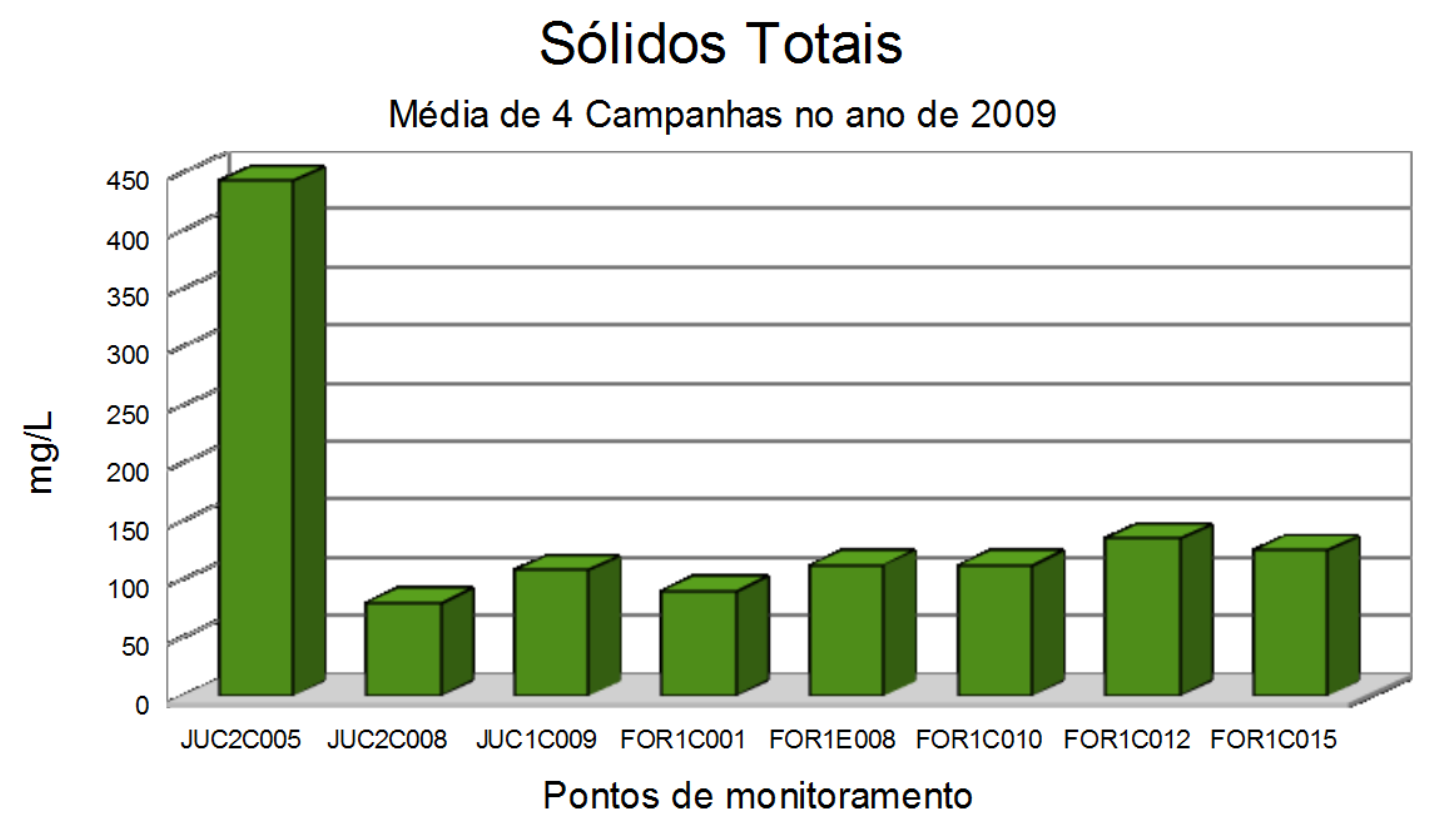

Figura 7: Pontos de monitoramento dos Sólidos Totais.

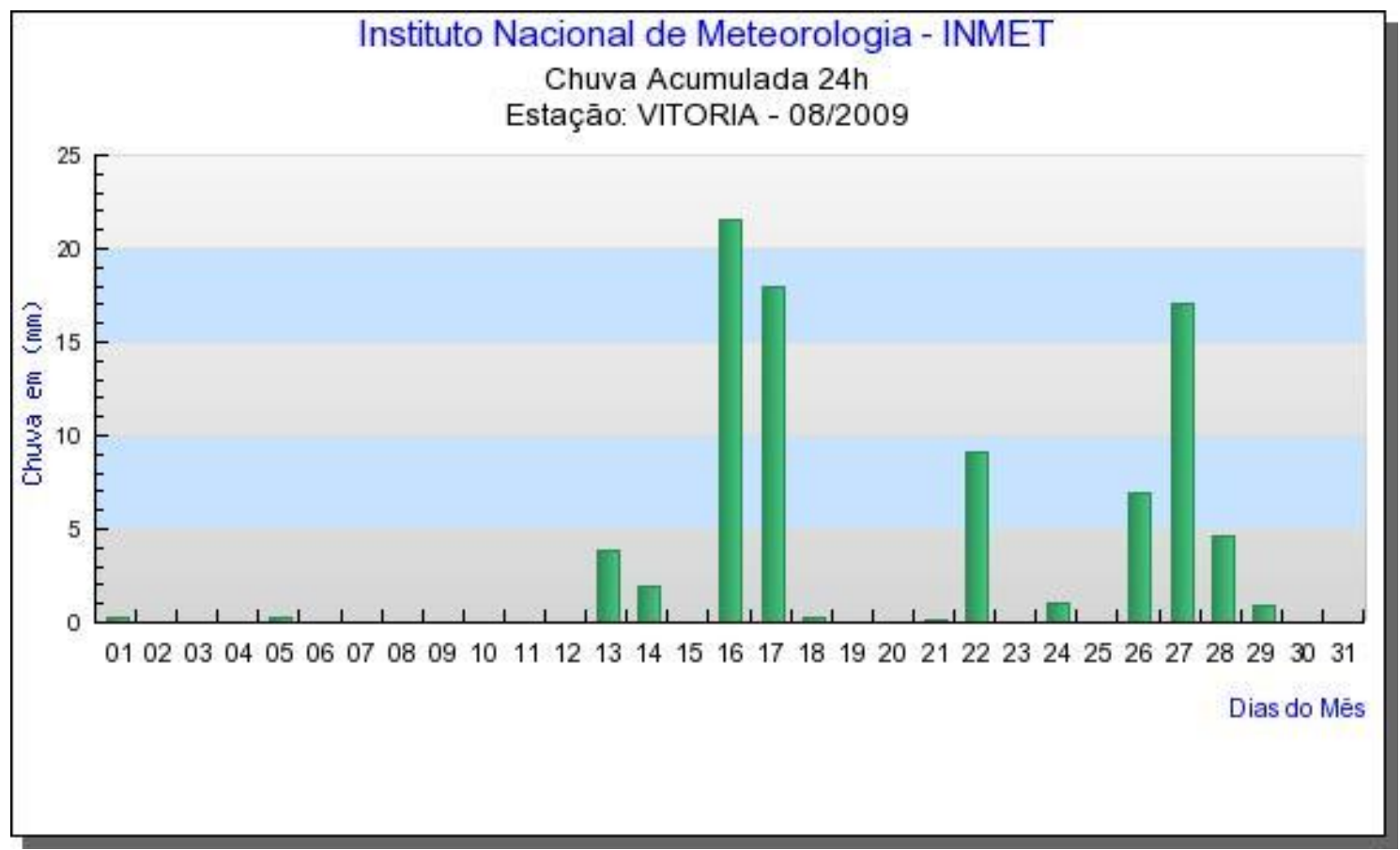

Figura 8: Índice Pluviométrico da região da Grande Vitória no mês de agosto de 2009 [29].

Almeida e Schwarzbold [30] utilizando IQA da NSF e monitorando uma sub-bacia com cerca de 9600 ha, constataram a baixa qualidade da água quando o nível do rio se encontrava nas maiores cotas, e devia-se à influência exercida por variáveis como turbidez, sólidos totais em suspensão e pH. Os resultados encontrados pelos autores citados anteriormente são típicos de bacias hidrográficas que possuem pouca ou nenhuma área de preservação, principalmente as de cursos d'água, cuja principal função dessas áreas é reter os sólidos providos da perda de solo transportados até os cursos d'água via escoamento superficial durante as chuvas intensas. Bonnet et al. [31] relacionando a qualidade da água e o uso do solo numa bacia hidrográfica em Goiás observaram também o que ocorreu neste estudo e afirmaram que, principalmente nos períodos de cheia, quando os piores valores de IQA são observados. 
Na Figura 9 é possível analisar os valores médios das 4 campanhas no ano de 2009, observados para coliformes termotolerantes.

A linha vermelha ilustra o limite padrão do CONAMA 357/2005 para a classificação de águas doce classe 2, para coliformes termotolerantes é de até $1000 \mathrm{NMP} / 100 \mathrm{ml}$.

Coliformes Termotolerantes

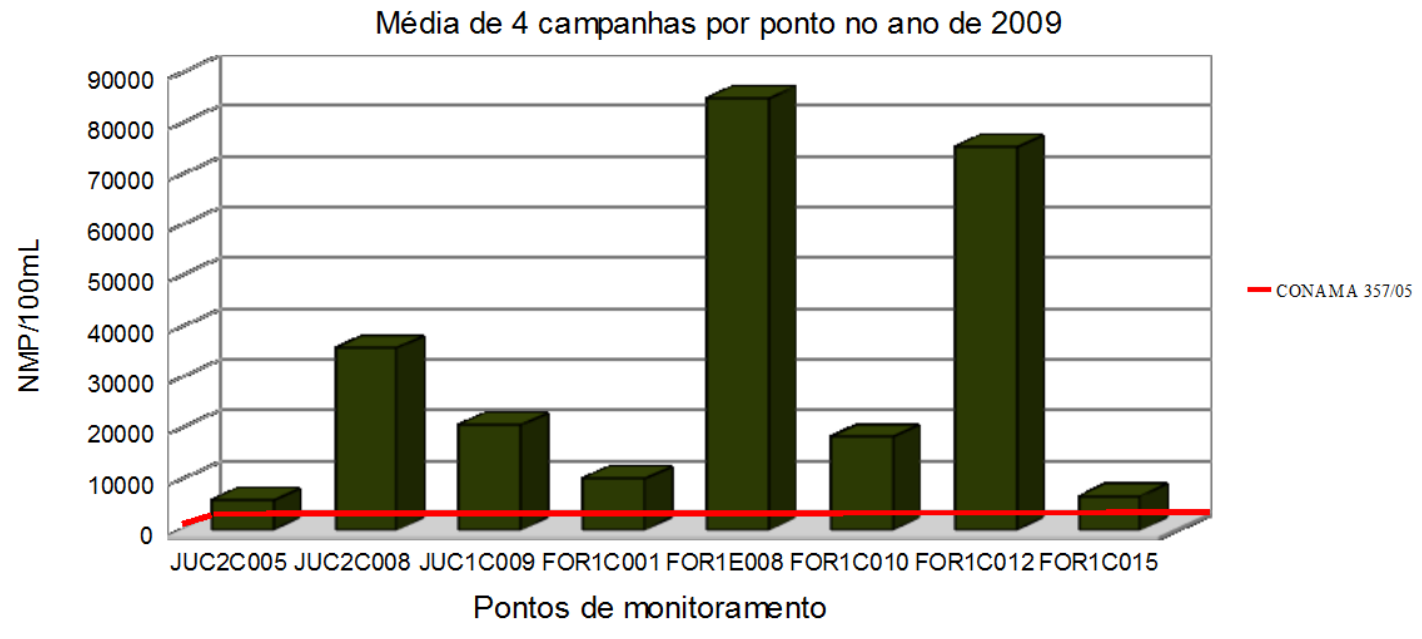

Figura 9: Pontos de monitoramento de Coliformes termotolerantes.

No rio Jucu Braço Sul, pode-se notar menores valores alcançados em relação aos pontos do rio Formate, pois a maioria dos pontos coletados encontra-se com menor variação entre os mesmos. Entretanto, no rio Formate, alguns pontos chamam a atenção são: FOR1E008 e FOR1C012, que apontam altos valores de coliformes termotolerantes. Valores próximos forma encontrados por Nunes et al. [23] quando analisou a qualidade das águas do rio turvo em Viçosa, MG afirmando ter influenciado fortemente no IQA. Conforme este autor e Von Sperling [3], os coliformes termotolerantes são indicadores de contaminação fecal e originária de fezes humanas ou outros animais, que segundo o mesmo autor, um corpo d'água contaminado com coliformes são indicadores, de antemão, vindo de esgotos que contêm matéria e organismos fecais. Assim, os resultados apontam que o rio Formate pode estar exposto ao lançamento clandestino de esgoto doméstico próximo aos pontos de coleta que tiveram os valores altos. $\mathrm{O}$ restante dos pontos: FOR1C001, FOR1C010 e FOR1C015 tiveram valores que não chega a $20.000 \mathrm{NMP} / 100 \mathrm{~mL}$, mas como referência padrão todos os pontos estão acima do limite estabelecido pelo CONAMA 357/05.

No que diz respeito à turbidez, a Figura 10 demonstra maiores valores no ponto JUC1C009, entretanto com pouca diferença entre os demais pontos da microbacia do rio Formate. 


\section{Turbidez}

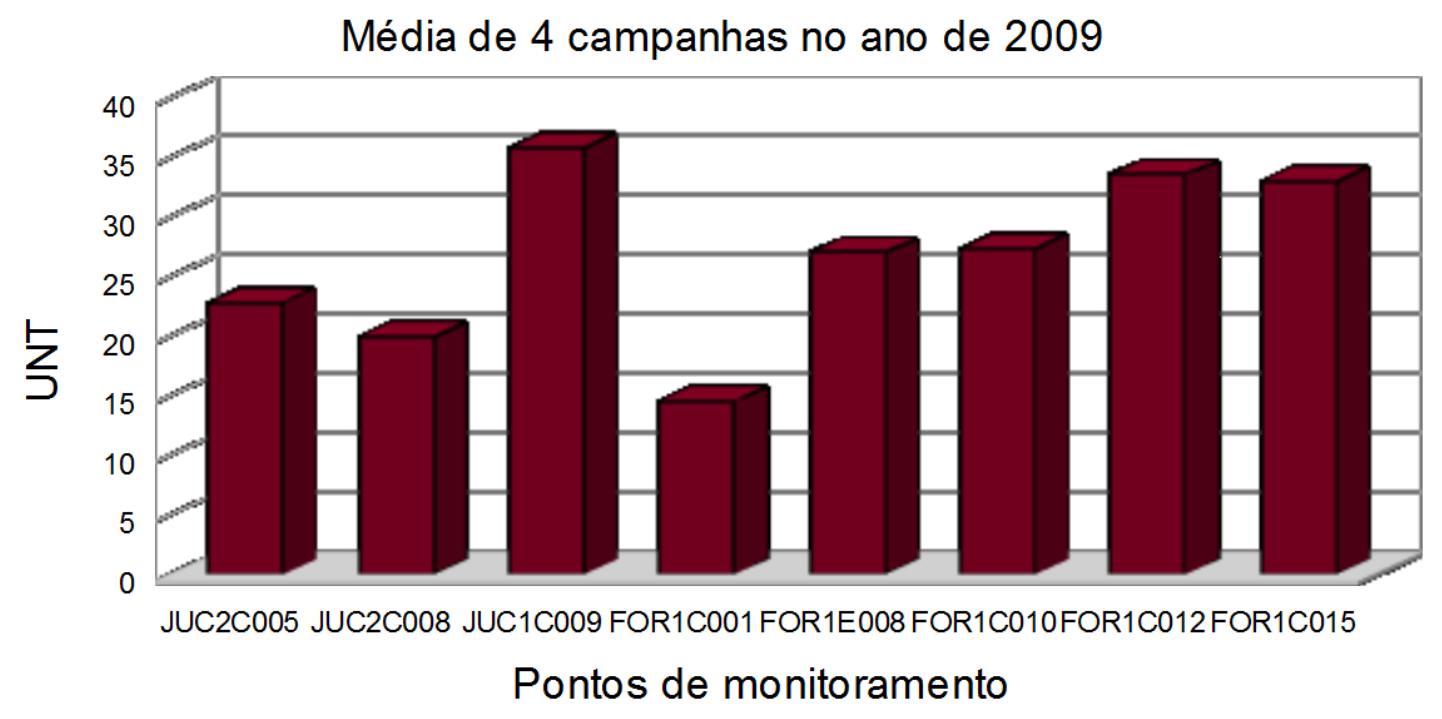

Figura 10: Pontos de monitoramento da Turbidez.

De maneira geral, a turbidez se mostrou dentro dos níveis estabelecidos pelo CONAMA 357/2005, o limite de turbidez estabelecido para rios de classe 2 é de até 100 UNT, o qual não foi excedido em nenhum dos pontos de monitoramento das duas microbacias estudadas.

A turbidez tem sido adotada por diversos estudiosos para a determinação da qualidade da água, geralmente associada à erosão acelerada ou ao lançamento de efluentes domésticos em cursos fluviais. Contudo, também tem sido enfocada no estudo de processos geomorfológicos de encosta e fluviais, sinalizando a dinâmica dos processos erosivos e sedimentares [32].

Quando se compara o IQA e o percentual de cobertura florestal, nota-se na Figura 11, que os pontos (JUC2C005, JUC2C008, JUC2C009) referentes à sub-bacia do rio Jucu Braço Sul, apresentam resultados de IQA com classificação "BOA". É apresentado como resultado esperado, devido à quantidade elevada de cobertura florestal nessa região de aproximadamente $70 \%$, ou seja, uma área preservada, com pontos de monitoramento de boa qualidade de água, protegidos das intempéries que possivelmente não recebe grandes cargas de poluentes ou ações antrópicas mais impactantes.

\section{IQA x \% Cobertura florestal}

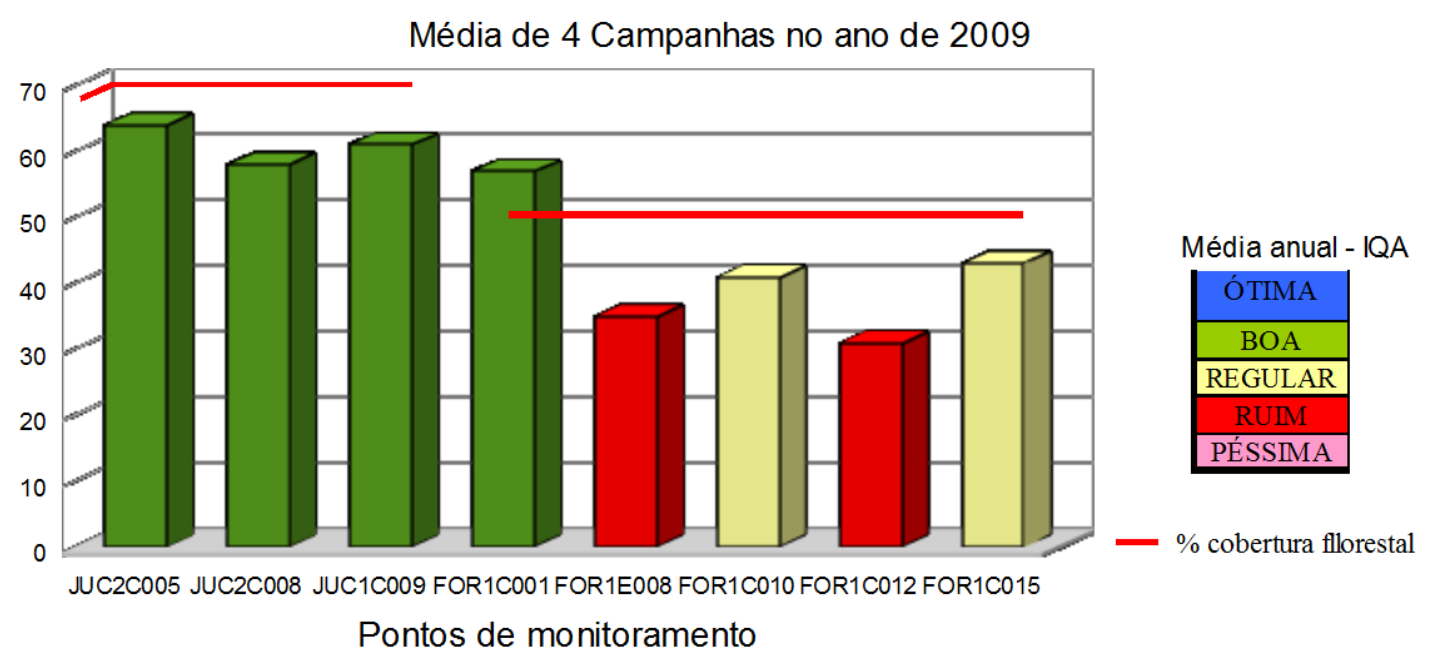

Figura 11: Gráfico do IQA em relação a cobertura florestal para cada ponto de monitoramento. 
Por outro lado, os pontos (FOR1C001, FOR1E008, FOR1C010, FOR1C012, FOR1C015) do rio Formate apresentam níveis mais baixos e com classificação em geral, para aqueles pontos, de "REGULAR" para "RUIM", exceto um ponto classificado como "BOM", o FOR1C001. O ponto classificado como "BOM", deve-se ao fato de se encontrar mais a montante e recebendo menores cargas de poluentes do que os pontos subsequentes. A microbacia do rio Formate encontra-se com uma cobertura florestal de aproximadamente $40 \%$ e esta cobertura está localizada principalmente a montante da bacia. Segundo Cruz [33] a degradação da qualidade das águas dessa localidade, deve-se pela realidade histórica de ocupação desordenada, ou seja, assentamentos próximos dos rios, com ações antrópicas mais impactantes e com exposição e lançamento de poluentes constantemente como pode ser observado na Figura 12.

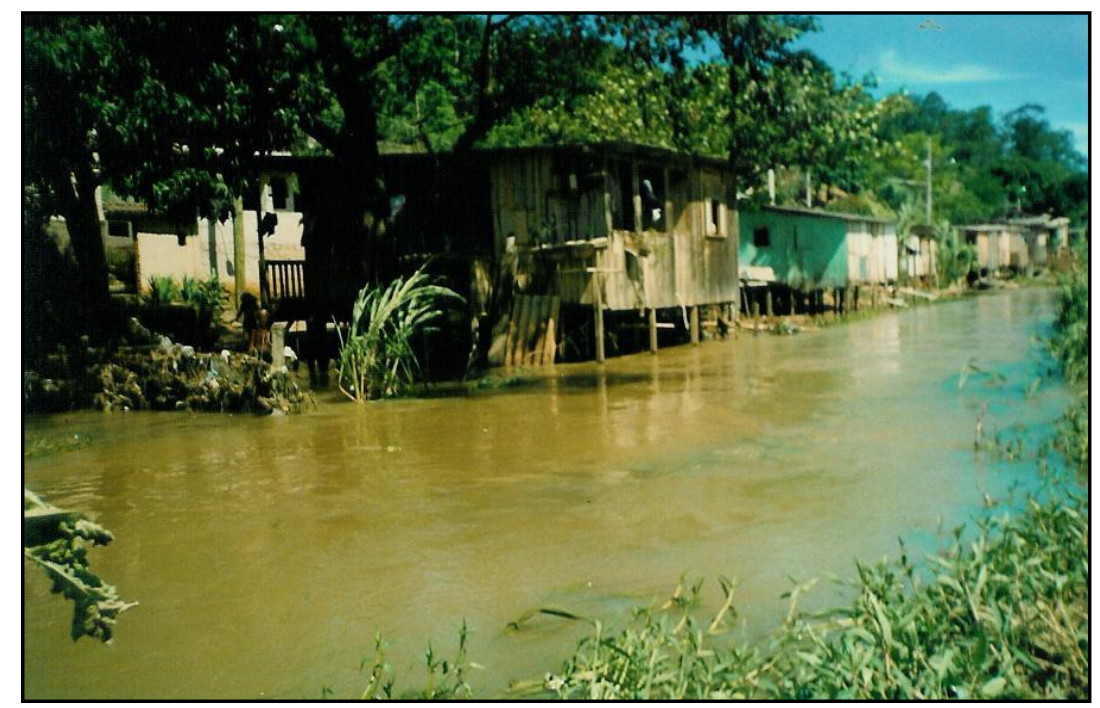

Figura 12: Palafitas sobre o canal fluvial do Rio Formate. Foto: Edmundo Cruz [33.

Bonnet et al. [31] afirmam que em estudo relacionando o uso e ocupação do solo e a qualidade da água, que o IQA é sensível às variações sazonais e responde ao aporte de sedimentos e matéria orgânica por escoamento superficial durante as estações chuvosas. Rocha et al. [34] acreditam que bacias com maiores proporções de cobertura vegetal e áreas ripárias protegidas apresentam melhor qualidade de água. Chaves e Santos [35] completam que não apenas a proporção mas também a posição das áreas florestadas na bacia influenciam a qualidade da água.

Ao se analisar os dados de coeficiente da variação, observa-se que os pontos JUC2C005, JUC2C008 e FOR1C001 apresentam variações menores ou iguais a 15\%, indicando baixa dispersão entre os dados, o que os caracterizam como dados homogêneos. Quanto aos demais pontos (JUC1C009, FOR1E008, FOR1E010, FOR1E012 e FOR1E015) apresentaram valores com média dispersão, não sendo homogêneos, tampouco heterogêneos. Os resultados provindos do coeficiente de variação corroboram com os já apresentados anteriormente. Os pontos do Rio Jucu e o ponto de cabeceira do Rio Formate (FOR1C001) apresentam melhores qualidades de água por estarem mais distante nas áreas urbanizadas, consequentemente menores variações na qualidade de água e índices de qualidade mais satisfatórios.

\section{CONCLUSÃO}

Ao se relacionar os parâmetros de qualidade da água à influência da cobertura florestal, os parâmetros que mais apontaram sofrer interferência foram: Nitrogênio total e Temperatura.

As variáveis Demanda Bioquímica de Oxigênio $\left(\mathrm{DBO}_{5}\right)$, Fósforo total, Turbidez, Sólidos totais e Coliformes termotolerantes, apontaram ter mais relação com impactos decorrentes de área urbana. 
A variável Sólidos Totais se manteve estável praticamente em quase todos os pontos monitorados, com exceção a um ponto na cabeceira do Rio Jucu (JUC2C005), estando este caso ligado possivelmente ao escoamento superficial de uma estrada próxima.

Observou-se no estudo a importância da preservação da cobertura florestal, sobretudo das áreas de preservação permanente marginais aos cursos d'água, uma vez que as sub-bacias estudadas abastecem a região metropolitana da Grande Vitória e como bacias com percentuais maiores de florestas produzem água de melhor qualidade o custo de tratamento será menor.

\section{AGRADECIMENTOS}

Os autores agradecem ao laboratório de monitoramento de Recursos Hídricos do Instituto Estadual de Meio Ambiente e Recursos Hídricos do estado do Espírito Santo (IEMA), cujos dados foram gentilmente cedidos.

\section{REFERÊNCIAS BIBLIOGRÁFICAS}

1. Sirigate P, Stadler CC, Oroski FI, Kovaleski JL. Gestão da qualidade ambiental da água de mananciais de abastecimento público como estratégia de redução de custos. XXX Encontro Nacional de Engenharia de Produção - Porto Alegre-RS; 2005.

2. Alves JMP, Castro PTA. Influência de feições geológicas na morfologia da bacia do Rio do Tanque (MG) baseada no estudo de parâmetros morfométricos e análise de padrões de lineamentos. Revista Brasileira de Geociências, Curitiba, jun. 2003;33(2):117-124.

3. Von Sperling M. Princípios do Tratamento Biológico de Águas Residuárias: Introdução à qualidade das águas e ao tratamento de esgotos. v. 1. 3. ed. Belo Horizonte: UFMG; 2005. 452 p.

4. Braga B, Hespanhol I, Conejo JGL. Introdução à engenharia ambiental. 2 ed. São Paulo: Pearson Prentice Hall; 2005.318 p.

5. Vieira CP. Alterações na cobertura vegetal: interferência nos recursos hídricos. Silvicultura, 2000; 20:26-27.

6. Iema, As Bacias Hidrográficas do Estado do Espírito Santo em 2003, disponível em: http://www.iema.es.gov.br, acesso em: 18 de fevereiro de 2010.

7. Lara AIE, Tosin PC. Ações para o manejo e gerenciamento de mananciais. In: Andreoli CV (org.). Mananciais de abastecimento: planejamento e gestão - estudo de caso do Altíssimo Iguaçu. Curitiba, Companhia de Saneamento do Paraná - Sanepar; Financiadora de Estudos e Projetos - Finep, 2003. p.: 401-426.

8. Meiman JR, Kunkle SM. Land treatment and water quality control. Journal of soil and water conservation. 1967;22(2):67-70.

9. Swift Junior LW, Messer JB. Forest cuttings raise temperatures of small streams in the southern Appalachians. Journal of soil and water conservation. 1971;26(3):111-117.

10. Cornish PM. Water quality studies in New South Wales State Forests: 1- a North coast eucalypt forest near Lismore. Australian forestry, 1980;43(2):105-110.

11. Swank WT, Crossley Junior DA. Forest hydrology and ecology at Coweeta. New York: SpringerVerlag; 1988. 469 p.

12. Alvares CA, Stape JL, Sentelhas PC, Gonçalves, JLM, Sparovek G. Köppen's climate classification map for Brazil. Meteorologische Zeitschrift. 2013;22(6):711-728.

13. Associação Brasileira de Normas Técnicas - ABNT. Preservação e técnicas de amostragem de efluentes líquidos e corpos receptores: 9898. Rio de Janeiro; 1987. 22 p.

14. American Public Health Association. Standard Methods for the Examination of Water and Wastewater. 20th. APHA; 2005.

15. Carvalho AP, Moraes Neto JM, Lima VLA, Silva DGKC. Determinação espacial e temporal do IQA do açude Soledade em Soledade - Paraíba. Engenharia Ambiental, Espírito Santo do Pinhal, , abr. / jun. 2011; 8(2):138 -147.

16. Brasil. Ministério do Meio Ambiente. Conselho Nacional do Meio Ambiente. Resolução no 357 de 17 mar. 2005. Diário Oficial da União n̊ 053, 17 mar. 2005, seção 1, pág. 58-63. Disponível em < http://www.mma.gov.br/port/conama/legiabre.cfm?codlegi=459> Acesso em: 03 abr. 2012.

17. Donadio NMM, Galbiatti JA, de Paula RC. Qualidade da Água de nascentes com diferentes usos do solo na Bacia Hidrográfica do Córrego Rico. São Paulo, Brasil. Engenharia Agrícola; 2005.

18. Esri ArcGIS - ArcMap 9.3 Help On Line. Redlands: ESRI; 2008. 
19. Ortofotomosaico Iema 2007/2008. Convênio "Vale de Qualidade Ambiental". Companhia VALE e Instituto Estadual de Meio Ambiente e Recursos Hídricos - IEMA; 2009.

20. Wrublack SC, Mercante E, Vilas Boas MA. Mapping of use and occupation of the soil and irrigation water quality in the city of Salto do Lontra-Paraná, Brazil. Eng. Agríc., Jaboticabal, oct. 2013;33(5) .

21. Silva AP. Comitês de Bacias Hidrográfica dos Rios Jucu e Santa Maria da Vitória. Documento Agenda das Bacias Estratégicas Rios Jucu e Santa Maria da Vitória. Instituto Ecobacia e Instituto Estadual de Meio Ambiente e Recursos Hídricos (IEMA), ES; 2009.

22. Zonta JH, Zonta JB, Rodrigues JI da S, Reis EF dos. Qualidade das águas do Rio Alegre, Espírito Santo. Rev. Ciên. Agron., Fortaleza, jan.- mar., 2008;39(1):155-161.

23. Nunes DG, Silva DD, Matos AT. Índice de Qualidade da Água em trechos do rio Turvo Sujo, Viçosa - MG. Engenharia na Agricultura, Viçosa, set./out. 2011;19(5):459-468.

24. Campello FD, Braga CF, Gonçalves CV, Gonçalves CS, Fuhro D, Santos Júnior JE dos, Rodrigues GG, Guerra T, Hartz SM. Avaliação preliminar da qualidade das águas da Floresta Nacional de São Francisco de Paula, RS, Brasil. Revista Brasileira de Biociências, Porto Alegre, jan./dez. 2005;3(1):009-046.

25. Terra VR, Santos RP, Aliprandi RB, Barcelos FF, Marbach PAS, Martins JLD, Azevedo Junior RR, Barbiéri RS. Monitoramento do rio Jucu Braço Sul: Caracterização e avaliação dos parâmetros físicoquímicos e microbiológicos. Natureza on line, Santa Teresa. 2009;7(1):5-11.

26. Tucci CEM, Mendes CA. Avaliação Ambiental Integrada de Bacia Hidrográfica. Ministério do Meio Ambiente / SQA. Brasília: MMA; 2006.

27. Lima WP. Hidrologia Florestal aplicada ao manejo de Bacias Hidrográficas. São Paulo: USP; 2008. $244 \mathrm{p}$.

28. Srinivasan VS, Santos CAG, Galvão CO. Erosão hídrica do solo no semi-árido brasileiro: a experiência na bacia experimental de Sumé. Revista Brasileira de Recursos Hídricos, abr./jun. 2003;8(2):57-73.

29. Instituto Nacional de Meteorologia - INMET. Brasília - DF. Gráficos das condições registradas. http://www.inmet.gov.br/sim/abre_graficos.php. Acesso em: 03 abr. 2012.

30. Almeida MAB, Schwarzbold A. Avaliação sazonal da qualidade das águas do Arroio da Cria Montenegro, RS com aplicação de um Índice de Qualidade de Água (IQA). Revista Brasileira de Recursos Hídricos, Porto Alegre, jan./mar. 2003;8(1):81-97.

31. Bonnet BRP, Ferreira LG, Lobo FC. Relações entre qualidade da água e uso do solo em Goiás: uma análise à escala da Bacia Hidrográfica. Revista Árvore, Viçosa. 2008;32(2):311-322.

32. Lopes FB, Andrade EM de, Aquino DN, Lopes JFB. Proposta de um índice de sustentabilidade do Perímetro Irrigado Baixo Acaraú, Ceará, Brasil. Revista Ciência Agronômica, abr./jun, 2009;40(2):185-193.

33. Cruz EA. Diagnóstico das Áreas de Susceptibilidade a Enchentes na sub-bacia do rio Formate. (Trabalho de conclusão de curso) Universidade Federal do Espírito Santo, UFES. Vitória; 2004.

34. Rocha JC, Rosa AH, Cardoso AA. Introdução à Química Ambiental. Porto Alegre: Bookman; 2004. $154 \mathrm{p}$.

35. Chaves HML, Santos LB dos. Ocupação do solo, fragmentação da paisagem e qualidade da água em uma pequena bacia hidrográfica. Revista Bras. Eng. Agríc. Ambiental, Campina Grande. 2009;13(6):922-930. 